Another way to measure the impact of continuous self-sanitizing materials is the examination of HAI rates. In the largest study of biocidal surfaces to date, Sifri et $\mathrm{al}^{3}$ found that HAI rates were reduced at statistically significant levels at a community hospital, allowing for the connection between reduced rates and the intervention of copper-impregnated surfaces.

Confounders further obfuscate the results. The study's snapshots of information would have been more meaningful if the amount of bioburden to which the surfaces were exposed had been quantified or if all the surfaces had been exposed to the same amount of bioburden. However, as mentioned in the study's limitations, no data were collected on how many individuals handled the surfaces, whether or not they used gloves, where the carts traveled, or which rooms they entered. All of these elements have been proven to impact bioburden and must be tracked for accurate analysis or recognized as confounders that prevent clear causation. As a result, the CFUs counted cannot be fairly compared from one surface to the next.

The conclusions drawn by the investigators are that copper formulations do reduce bioburden compared to stainless steel, but this efficacy is reduced after continuous use in the field. I believe the study cannot make this claim without addressing either the limitations of the study (no information about surface exposure) or the design of the study (isolated snapshots rather than tests over time). The conclusions reached by the authors, while positive overall about the potential for copper formulations in healthcare, make implications about efficacy that could have significant impact on the reputation and adoptions of these potentially life-saving products.
Self-sanitizing materials are new. Even seasoned professionals find that they must shift paradigms when considering a product that works to continuously reducing bioburden over time. The novice professional or healthcare professional not involved in infection prevention would have an even steeper learning curve to conceptualize the benefits of such a product in reducing hospital-associated infections. Therefore, researchers investigating these new products must take extra steps to make sure they are testing what they claim to be testing and whether the literature contains proven methods they can use to reach the most valid conclusions possible.

\section{Acknowledgments.}

Financial support. No financial support was provided relevant to this article.

Conflicts of interest. All authors report no conflicts of interest relevant to this article.

\section{References}

1. Bryce E, Velapatino B, Donnelly-Pierce T, et al. Antimicrobial efficacy and durability of copper formulations over one year of hospital use. Infect Control Hosp Epidemiol 2021. doi: 10.1017/ice.2021.52.

2. Coppin JD, Villamaria FC, Williams MD, et al. Self-sanitizing copperimpregnated surfaces for bioburden reduction in patient rooms. Am J Infect Control 2017;45:692-694.

3. Sifri CD, Burke GH, Enfield KB. Reduced health care-associated infections in an acute care community hospital using a combination of self-disinfecting copper-impregnated composite hard surfaces and linens. Am J Infect Control 2016;44:1565-1571.

\title{
Estimated incidence rate of healthcare-associated infections (HAIs) linked to laundered reusable healthcare textiles (HCTs) in the United States and United Kingdom over a 50-year period: Do the data support the efficacy of approved laundry practices?
}

\author{
Michael R. Overcash $\mathrm{PhD}^{1}$ and Lynne M. Sehulster $\mathrm{PhD}^{2}$ \\ ${ }^{1}$ Environmental Genome Initiative, Raleigh, North Carolina and ${ }^{2}$ Environmental Infection Prevention, Lawrenceville, Georgia
}

To the Editor - The assumed transmission of healthcare-associated infections (HAIs) from reusable healthcare textiles (HCTs) has been a perception in the decisions to use disposable versions of these textile items. ${ }^{1-4}$ Here, we compared the 50 -year publication record of HAIs related to laundry of HCTs to the overall actual occurrence of HAIs in hospitals over the same 50 years.

To reduce the risk of HAIs from reusable HCTs (ranging from linens to isolation gowns to surgical gowns), the reprocessing of these items involves a laundry process that renders the HCTs hygienically clean. In a well-studied database by Sehulster ${ }^{5}$ of all outbreak events published between 1970 and 2013, laundered, clean HCTs were implicated as a source of contamination leading

Author for correspondence: Michael R. Overcash, E-mail: mrovercash@earthlink.net Cite this article: Overcash MR and Sehulster LM. (2022). Estimated incidence rate of healthcare-associated infections (HAIs) linked to laundered reusable healthcare textiles (HCTs) in the United States and United Kingdom over a 50-year period: Do the data support the efficacy of approved laundry practices?. Infection Control \& Hospital Epidemiology, 43: 1510-1512, https://doi.org/10.1017/ice.2021.274 to HAIs. Root causes linked to the introduction of microbial contamination of the laundered HCTs were mostly mechanical problems with laundry equipment or the occurrence of inadvertent environmental contamination. The Sehulster review followed the methodology of PRISMA ${ }^{6}$ and was peer reviewed. This same methodology was then used for the period of 2013-2020 and we found 3 more studies ${ }^{7-9}$ and another review, ${ }^{10}$ making the scope of this analysis 1970-2020.

For the purposes of the present assessment of reusable HCTs versus disposable alternatives, we have combined the United States and United Kingdom incidences of HCT laundry-associated HAIs in the 50-year period (1970-2020). Based on available national data, the HAI rate as a percentage of population for the United Kingdom and the United States in $~ 1995$, appears to be similar, $0.5 \%-0.6 \%$ of population, which is near the midpoint of the 50 years of covered in this HAI study (Table 1). In these past 50 years for the United Kingdom and the United States, the 10 published events involved 69 patients with HAIs attributed to reusable 
Table 1. Available Data on HAls in the United States and United Kingdom from 1972 to 2018

\begin{tabular}{|c|c|c|c|c|}
\hline Year & Cited Annual HAI Cases in US or UK Hospitals, Millions & Source & US or UK Population, Millions & $\mathrm{HAI}, \%$ of US or UK Population \\
\hline 1974 & 1.6 & Sencer et al $1974^{12}$ & 213 & 0.75 \\
\hline 2009 & 1.7 & Zimlichman et al $^{14}$ & 307 & 0.55 \\
\hline 2011 & 0.3 & UK House of Commons ${ }^{15}$ & 61 & 0.49 \\
\hline 2018 & 1.2 & $\mathrm{AHA}^{17}$ & 327 & 0.37 \\
\hline
\end{tabular}

HCTs including patient gowns and other garments, bed linens (ie, sheets, pillows and pillow cases, blankets, towels), and in 1 instance mop pads for environmental cleaning of floors. ${ }^{5}$

We documented the United States and United Kingdom average actual HAI rates of cases/year over these 50 years (Table 1). This average for the United States plus the United Kingdom was $\sim 2.0$ million cases per year at the 1995 midpoint. Thus, the total number of HAI cases in the United States plus the United Kingdom over this entire 50-year period was $\sim 100$ million actual cases $(5,500$ HAI cases per day in the US plus UK populations).

Based on the 69 HAIs attributed to laundered HCTs over 50 years, we further added a very high speculation factor that infections related to reusables may be underreported by using 100 times the reported laundry-related HAIs to do this risk analysis. Thus, the laundry-related HAIs were scaled to 6,900 in the entire 50 years of record ( 0.37 cases per day). That is, 69 was assumed to represent only $1 \%$ of the total laundry-related HAIs occurring as unreported. With this conservative upper estimate, this would mean that instead of the reported incidence $\sim 1$ incident per year across these 50 years, we would expect to see upward of $100 \mathrm{HAI}$ cases per year in the United States and United Kingdom combined attributable to laundered HCT, which seems unlikely based on reported practices, lawsuits, published notes, etc. Thus, the 100 -fold factor seems conservative.

With this conservative estimate, the laundry-implicated HAIs in 6,900 patients for the United States and the United Kingdom over the past 50 years is $\sim 0.37$ HAI case per day (2.6 HAI per week). The estimated total healthcare HAI for the United States and United Kingdom over this same period is 5,500 cases per day (38,000 cases per week) (Table 1$)$. Thus, in probability terms, the chance of a patient having an HAI linked to contact with the laundered, reusable textile is $\sim 1$ in $14,900(5,500 / 0.37=14,900)$. As a reference, a person in the United States and the United Kingdom is more likely, based on the odds, to be struck by a meteor in any given year over a 78.5-year lifespan, which is 1 in $9,000 .^{18}$

Regarding cost, numerous articles acknowledge that on an annual basis, disposable textile items are more expensive compared to the cost of reusable textiles. ${ }^{19-21} \mathrm{~A}$ recent economic analysis found that the disposables were approximately twice as expensive on an annual basis. ${ }^{22}$

In conclusion, the healthcare system is paying annually on the order of $10 \%-100 \%$ more for disposable HCTs with a risk improvement of $\sim 2.6$ HAI per week in the United States and the United Kingdom, which would lower the HAI rate of these (combined) nations from 32,900 per week to 32,897 per week. This low risk of infection attributed to reusable HCTs is the basis for the Centers for Disease Control and Prevention's (CDC) acknowledgment of the historical record of patient safety and extremely infrequent episodes of infection linked to these clean HCTs. Furthermore, the CDC concluded that the need to establish a healthcare laundry certification program based on microbiologic testing of cleaned, reusable HCTs does not appear to be supported by epidemiologic data. ${ }^{5,23}$ In conclusion, the annual cost savings from selecting reusable HCTs does not come with any measurable increased risk of HAI to patients and therefore represents a prudent healthcare facility decision. With the COVID-19 pressure on PPE, reusables are increasing substantially and so the results herein should build confidence in these decisions.

\section{Acknowledgments.}

Financial support. No financial support was provided relevant to this article.

Conflicts of interest. All authors report no conflicts of interest relevant to this article.

Supplementary material. To view supplementary material for this article, please visit https://doi.org/10.1017/ice.2021.274

\section{References}

1. Tano E, Melhus A. Level of decontamination after washing textiles at $60^{\circ} \mathrm{C}$ or $70^{\circ} \mathrm{C}$ followed by tumble drying. Infect Ecol Epidemiol 2014;4:2431424320.

2. Moore G, Griffith C. A laboratory evaluation of the decontamination properties of microfiber cloths. J Hosp Infect 2006;64:379-385.

3. Fijan S, Šostar Turk S. Hospital textiles, are they a possible vehicle for healthcare-associated infections? Int J Environ Res Public Health 2012;9:33303342 .

4. Tajeddin E, Rashidan M, Razaghi M, et al. The role of the intensive care unit environment and health-care workers in the transmission of bacteria associated with hospital acquired infections. J Infect Public Health 2016;9:13-23.

5. Sehulster, L. Healthcare laundry and textiles in the United States: review and commentary on contemporary infection prevention issues. Infect Control Hosp Epidemiol 2015;36:1073-1088.

6. Moher D, Liberati, A, Tetzlaff J, Altman DG, The PRISMA Group (2009). Preferred reporting items for systematic reviews and meta-analyses: the PRISMA statement. BMJ 2009;339:b2535.

7. Cheng V, Chen J, Wong S, et al. Hospital outbreak of pulmonary and cutaneous zygomycosis due to contaminated linen items from substandard laundry. Clin Infect Dis 2016;62:714-721.

8. Teal L, Schultz K, Weber D, et al. Invasive cutaneous rhizopus infections in an immunocompromised patient population associated with hospital laundry carts. Infect Control Hosp Epidemiol 2016;1:1251-1253.

9. Boonstra M, Spijkerman D, Voor in 't holt A, et al. An outbreak of ST307 extended-spectrum beta-lactamase (ESBL)-producing Klebsiella pneumoniae in a rehabilitation center: an unusual source and route of transmission. Infect Control Hosp Epidemiol 2020;41:31-36. 
10. Owen L, Laird K. The role of textiles as fomites in the healthcare environment: a review of the infection control risk. Peer J 2020;8:e9790.

11. Haley R, Culver D, White J, et al. The efficacy of infection surveillance and control programs in preventing nosocomial infections in US hospitals. Am J Epidemiol 1985;121:182-205.

12. Sencer D, Axnick D. Utilization of cost-benefit analysis in planning prevention programs. Acta Med Scand 1974;Suppl 576:123-129.

13. Klevens R, Edwards J, Richards C, et al. Estimating healthcare-associated infections and deaths in US hospitals, 2002. Public Health Rep 2007;122:160-166.

14. Zimlichman E, Henderson D, Tamir O, et al. Healthcare-associated infections, a meta-analysis of costs and financial impact on the US healthcare system. JAMA Intern Med 2013;173:2039-2046.

15. House of Commons Library Research Service. Raising standards of infection prevention and control in the NHS. House of Commons Library, No. CDP2018-0116, 23. US Parliament website. https://commonslibrary.parliament. uk/research-briefings/cdp-2018-0116/. Published May 14, 2018. Accessed April 9, 2020.

16. Fast facts on US hospitals (2015 survey). American Hospital Association website. https://www.aha.org/system/files/2018-01/fast-facts-us-hospitals2017_0.pdf. Accessed March 31, 2020.
17. Fast facts on US hospitals (2018 survey). American Hospital Association website. https://www.aha.org/system/files/2020-01/fast-facts-us-hospitals2020_0.pdf. Accessed March 31, 2020.

18. Tamarchi M. What are the odds? How Stuff Works website. https://health. howstuffworks.com/diseases-conditons/death-dying/odds-of-death.htm. Accessed May 2, 2020.

19. Laufman H, Belkin N, Meyer K. A critical review of a century's progress in surgical apparel: how far have we come? Surg Apparel 2000;191: 554-568.

20. Rutala W, Weber D. A review of single-use and reusable gowns and drapes in health care. Infect Control Hosp Epidemiol 2001;22:248-257.

21. Gruendemann B. Taking cover: single-use vs. reusable gowns and drapes. Infect Control Today 2002;6:32-34.

22. Overcash M, Griffing E, National Economic Comparisons of Reusable and Single-Use Cleanroom Textile Products. Shawnee Mission, KS: American Reusable Textile Association; 2019: 8 pp.

23. CDC/HICPAC Guidelines for environmental infection control in healthcare facilities. Centers for Disease Control and Prevention website. https://www.cdc.gov/hicpac/pdf/guidelines/eic. Published 2003, updated July, 2019. Accessed March 31, 2020.

\title{
Change in trends of hospitalizations and deaths with mention of Clostridioides difficile infection in northeastern Italy, 2008-2019
}

\author{
Stefania Bellio $M D^{1}$ (1), Ugo Fedeli $M D^{1}$, Elena Schievano $M D^{1}$ and Mario Saia MD \\ ${ }^{1}$ Azienda Zero, Veneto Region, Padua, Italy
}

To the Editor-According to a recent systematic review, the incidence of Clostridioides difficile infection (CDI, previously known as Clostridium difficile infection) decreased from 2005 to 2015 in most European countries and have stabilized in North America, possibly due to active diseases surveillance, reinforced antibiotic stewardship, and stringent infection control policies. ${ }^{1}$ Namely in England, analyses of hospital episode statistics demonstrated a peak in CDI incidence in 2006-2007 followed by a steep decline. ${ }^{2}$ Mention of CDI in death certificates followed a similar pattern. ${ }^{3}$

Nonetheless, such favorable trend does not involve all European countries. In Spain, CDI-related hospitalizations increased between 2001 and 2015, both in analyses of primary and secondary discharge diagnoses, possibly reflecting an increase in the incidence of the infection, in the severity of the cases affected, or a greater awareness of the problem by clinicians with enhanced searching for cases. ${ }^{4}$

Recent reports suggest that coronavirus disease 2019 (COVID19) prevention measures might affect the risk of $\mathrm{CDI}^{5}$; however, baseline data on recent trends in Italy are lacking. Surveillance of CDI is still not active at the national level in Italy, nor in the Veneto region (northeastern Italy, about 4,900,000 inhabitants). In the absence of laboratory-based surveillance, in a previous report analyzing hospital discharge diagnoses and causes of death data, an increase in CDI rates was demonstrated in Veneto from 2008 to $2013 .{ }^{6}$ We updated previous figures to determine whether this unfavorable trend continued in 2019.

Author for correspondence: Stefania Bellio, E-mail: stefania.bellio@azero.veneto.it Cite this article: Bellio S, et al. (2022). Change in trends of hospitalizations and deaths with mention of Clostridioides difficile infection in northeastern Italy, 2008-2019. Infection Control \& Hospital Epidemiology, 43: 1512-1513, https://doi.org/10.1017/ice.2021.317
Discharges with primary or secondary CDI diagnosis using International Classification of Diseases, Ninth Revision, Clinical Modification (ICD-9-CM) code 008.45 were extracted from the regional archive of discharge records for patients aged $\geq 1$ year in the period from January 1,2008 , to December 31,2019 . In total, 9,787 records were identified, and among them $32.7 \%$ had CDI as the primary diagnosis and $73.8 \%$ were elderly ( $\geq 75$ years). The overall rate of CDI diagnosis per 1,000 discharges was 1.6, and it increased with age, reaching its highest $(5.1 \%$ ) among the very elderly ( $\geq 85$ years). The rate increased slightly during 2008-2019, with a peak in $2015(2.5 \%$ ). The population-based rates showed an even much steeper increase with age, with 16.9 CDI diagnoses per 100,000 population and a rate of 214.2 among the very elderly. The joinpoint regression analysis highlighted a significant increase of population-based rates from 2008 to 2015 (annual percentage change [APC], 14.0; 95\% CI, 10.0-18.1; $P<.001)$ and decreases in the following years (APC, -7.3 ; 95\% CI, -14.8 to 0.7 ; $P=.10$ ), with a peak of 25.1 per 100,000 population in 2015 . A similar trend was observed for discharges with CDI as primary diagnosis (Fig. 1).

In addition to hospitalization data, the regional mortality records were analyzed. The ICD-10 code for CDI, A047, was retrieved from records of multiple causes of death for 20082019. In total, 1,317 mortality records were identified, and $43.6 \%$ had CDI as the underlying cause of death. Most deaths (52.6\%) involved the very elderly, $84.7 \%$ were among hospitalized patients, and $10.1 \%$ were among those from long-term care facilities. The mortality rate per 100,000 population increased during this period, from 0.8 in 2008 to 2.2 in 2019 and reaching a peak of 3.7 in 2015 (Fig. 1). The rate significantly increased during 